\title{
Study on effect of laser keyhole weld termination regimes and material composition on weld overlap start-stop defects
}

\author{
Wai Jun Lai ${ }^{1}$, Supriyo Ganguly ${ }^{1}$, Wojciech Suder ${ }^{1}$ \\ Welding Engineering and Laser Processing Centre - Cranfield University, Cranfield, Bedfordshire, MK43 OAL, United Kingdom \\ Corresponding author. Email: wai-jun.lai@cranfield.ac.uk
}

\begin{abstract}
The effects of two different laser termination regimes; laser power ramp-down and laser defocusing, on the weld overlap start-stop region, have been studied on three different compositions of $\mathrm{S} 355 \mathrm{~J} 2+\mathrm{N}$ grade steel plates. The plates have varying amounts of deoxidisers, such as manganese and silicon, to allow for the effect of dissolved oxygen on melt pool dynamics and defect formation to be studied. Observations show that gas entrapment, manifesting as porosity, is the main issue in both the laser termination regimes studied, due to melt pool instabilities related to keyhole termination. However, it is more severe during laser defocusing due to the formation of porosity clusters below a specific power density and melt pool size. The percentage of dissolved oxygen and deoxidisers was found to be vital and could be correlated to the response of the melt pool during laser processing. Steel, with a higher percentage of deoxidisers, such as manganese and silicon, would combine with the dissolved oxygen in the weld pool and thereby affect the surface tension and melt pool dynamics. The effect of lower dissolved oxygen would lead to a reduction in penetration depth, but more importantly, porosity and porosity cluster formation, as observed for both laser termination regimes.

Successful laser termination with defect-free weld overlaps at the start-stop region could be achieved using both termination regimes for the steel with a higher proportion of deoxidising elements.
\end{abstract}

\section{Keywords}

Laser keyhole welding; Laser power ramp-down; Laser defocusing

\section{Introduction}

In recent years, construction industries involved in the joining of thick section marine structural steels, such as shipbuilding, oil and gas, and offshore wind, has grown. As a result, the demand for welding processes that are capable of deeper penetration, improved quality and higher productivity welds has also increased. Therefore, significant research and development have gone into high power and high energy density welding processes, such as laser keyhole welding and hybrid laser-arc welding (HLAW). In some shipbuilding industries, the success of HLAW research and development has led them to incorporate this welding process for the fabrication of large panels by longitudinal butt-welding [1,2]. The high energy density of the laser leads to material vaporisation and the formation of a keyhole, which leads to deeper penetration welds at relatively higher welding speeds. However, this phenomenon also makes the process 
highly sensitive to variation in the process parameters and melt pool dynamics, which can lead to keyhole instabilities and, therefore, keyhole collapse during welding.

Keyhole instabilities that result in keyhole collapse can lead to the formation of large porosity type defects and voids due to gas/vapour entrapment, as was shown through numerical modelling $[5,6]$. The authors explained and demonstrated the complex keyhole dynamics and balance of the driving forces, such as vapour recoil pressure that keeps a keyhole open, and the surface tension and hydrodynamic pressures that close a keyhole. Imbalanced interaction of these forces may result in the formation of protrusions which can grow and lead to keyhole instability and subsequent collapse during welding.

These issues are especially severe at the end of a welding process where changes in the process parameters are necessary for laser termination. During laser termination, there are several phenomena which need to be considered, each occurring within a specific time frame. The extinction of plasma from the formed keyhole, the decay of vaporisation recoil pressure and the mechanical collapse of the keyhole driven by surface tension forces, all occur before the keyhole collapses [3]. Abrupt termination of the laser also causes a sudden drop in the vaporisation recoil pressure resulting in an imbalance of the driving forces, which may lead to keyhole collapse and formation of pores or voids [4]. Adverse material shrinkage can also lead to defects, such as porosity, cracking, keyhole cavities and craters to form during laser termination. The laser may leave a partially filled keyhole at the termination point when the laser is terminated abruptly or without adequate control of the process parameters. Hence why laser keyhole and HLAW processes are popular for longitudinal welds where run on and off plates are welded to each edge of the workpiece to contain any laser initiation and termination defects and are then subsequently removed. For circumferential welding of tubular sections, such as pipes, this procedure is not feasible due to the intersecting weld overlap. The initiation and termination points where defects are more likely to occur, therefore, remains within the workpiece. In full penetration autogenous laser keyhole welding, the filling of a keyhole cavity at the laser termination point is even more difficult as there is no addition of filler material. Further understanding and methods of mitigation for laser keyhole termination is required.

Mitigation methods for laser termination, such as laser power-ramp down and laser defocusing has shown promise in eliminating defects in the weld overlap start-stop region for different laser processing applications, such as laser welding of relatively small thicknesses [5], and laser cladding of pipes [6]. For laser keyhole, circumferential welding applications of thick section structural steels, a more in-depth understanding of the effects of laser termination regimes on defect formation is necessary. Welding of thicker sections poses further challenges due to the higher laser powers required to achieve full penetration welds. Defect formation in high laser power and thick section 
welding such as cracking, root humping and sagging, surface underfill, undercuts, and root porosity, have been investigated by several authors [7-11]. The higher solidification stresses and material shrinkage associated with thicker plate thicknesses can lead to crack formation. Root instabilities related to the laser energy, vapour recoil pressure, melt pool flow and surface tension, can lead to surface underfill, undercuts and root porosity. As previously mentioned, there is a delicate balance of forces required to maintain keyhole stability in full penetration welds, which is made more difficult in thick section welding.

Until recently, there has been limited research into the application of laser termination regimes for thick section circumferential welding. Gook et al. [12] conducted studies on autogenous laser keyhole welding of $8 \mathrm{~mm}$ thick sections using both laser power-ramp down, and laser defocusing termination regimes. The authors showed that both termination regimes are prone to root sagging defects that increase with ramp-down or defocusing distances. The root sagging is due to the transition from full penetration to partial penetration welding and the accumulation of excessive heat. Gook et al. observed that end crater cracks increased with the weld distance and that they varied with the amount of laser defocusing applied. Unfortunately, with the laser defocusing process window used in the study, the formation of end crater cracks could not be avoided, and a remedial weld using a defocused laser beam was necessary.

Furthermore, successful experimental demonstrations of laser power ramp-down on 8 $\mathrm{mm}$ thick circumferential welds of A304 stainless steel tubes using HLAW was achieved [13]. However, the author only demonstrated the possibility of successful keyhole closure without significant defects at the laser termination point using one case of laser power ramp-down parameters. There is still little research showing a comprehensive understanding of laser keyhole termination for different processing conditions and different approaches of laser terminations on defect formation. The same strategy may not be appropriate for all cases; therefore, a more comprehensive understanding is necessary. Different mitigation methods such as, laser power ramp-down and laser defocusing, have different effects on microstructural development due to changes in laser material interaction parameters. These changes result in different heat inputs, cooling rates and weld profiles, which can lead to various defects occurring if not adequately understood, controlled, and applied.

Melt pool dynamics are not only affected by process parameters, but also by the material composition. Individual elements can have significant effects on material vaporisation, melt pool flow and surface tension. Elements, which are key deoxidisers in steelmaking, such as manganese, silicon and aluminium will affect the amount of dissolved oxygen in the molten material. Surface-active elements, such as oxygen and sulphur affect the surface tension and flow direction of the melt pool which can lead to changes in penetration depth and melt pool stability, resulting in surface ripples and 
different weld profiles [14,15]. Differences in weld bead geometries and weld profiles were observed in Cold Metal Transfer (CMT) Gas Metal Arc Welding (GMAW) when using three different filler wires with varying manganese, silicon and oxygen content [16]. The authors showed how slag formation and accumulation location changes with varying composition wires due to different flow behaviour because of changes to the temperature gradient of the surface tension. Low manganese and silicon content wires had higher concentrations of dissolved oxygen, which resulted in a positive temperature gradient of the surface tension, leading to inward directional material flow. The opposite result for wires with high manganese and silicon content was observed. Several authors observed similar flow behaviour as well as an increase in penetration depth in laser welding when adding oxygen through the shielding gas [17-19]. However, both Ribic et al. [18] and Zhao et al. [19] attributed the increase in penetration depth with increasing oxygen concentration to the formation of carbon monoxide inside the keyhole instead of to the effect of Marangoni flow and surface tension. Through computation and experimental studies, the authors showed that the calculated values of the temperature gradients and surface tension at the keyhole were similar under different concentrations of both oxygen addition and sulphur despite increases in penetration depth. The formation of carbon monoxide by the reaction between dissolved carbon and oxygen can result in additional pressure in the keyhole, leading to increased penetration. Steel compositions with different chemical compositions and oxygen from the atmosphere will influence vaporisation temperature and recoil pressure, resulting in different laser keyhole weld behaviour and weld profiles.

Currently, the understanding and development of laser termination regimes in laser keyhole welding has only started to emerge. Further research is necessary to allow for the adaptation of laser keyhole welding for circumferential welding of thick section structural steels. This paper shows a two-part experimental study on the effect of two different laser termination regimes, laser power ramp-down and laser defocusing on three different steel compositions. Firstly, the defect formation occurring in the circumferential weld overlap area as a result of laser termination using different termination regimes was shown. Secondly, the effect of varying chemical composition of S355J2+N grade steel plates, manufactured with different deoxidation practices, on laser welding and keyhole closure mechanism were studied. Successful laser termination of full penetration autogenous laser welds was obtained using both laser power ramp-down and laser defocusing on $8 \mathrm{~mm}$ thick plates.

\section{Experimental procedure}

In this study, two experiments were carried out to investigate different laser termination regimes at the weld overlap start-stop region of varying chemical composition $\mathrm{S} 355 \mathrm{~J} 2+\mathrm{N}$ grade steel plates. Firstly, the effect of two laser termination regimes, laser power ramp-down and laser defocusing, on laser termination and defect formation was 
studied. In the second experiment, the impact of varying chemical composition $\mathrm{S} 355 \mathrm{~J} 2+\mathrm{N}$ grade structural steel on laser termination regimes was studied.

\subsection{Replicated circumferential weld on flat plate}

A circumferential weld involves the joining of two tubular structures, such as pipes or tubes, along the circumference. The starting position is overlapped by the intersecting weld before termination and remains within the workpiece. Circumferential welding was simplified by replicating the process onto a flat plate. Two partially overlapping bead-onplate weld seams with an elongated overlap region were replicated onto a flat plate, as shown in Fig. 1. This approach allows for any circumference to be replicated by varying the time in-between the two weld seams.

Each point denoted as $A, B, C$, and $D$ represents the two initiation points $(A$ and $B$ ) and two termination points $(C$ and $D)$ of the two bead-on-plate welds. The first weld seam is conducted from point $B$ to point $D$, and the second weld seam is carried out from point $A$ and terminating at point $C$. The intentionally elongated weld overlap $(\overrightarrow{\mathrm{BC}})$ allows for the initiation and termination points of the replicated circumferential weld seam, points $B$ and $\mathrm{C}$, to be studied independently. The plate was left to cool down to room temperature after performing the first weld seam. By doing so, the effect of inter-pass temperature and residual heat on the weld start and stop region is mitigated.

Point $A$ replicates the initiation point of a longitudinal weld and would be representative of point $\mathrm{B}$, had it not been overlapped by the second weld seam. The termination point $D$ of the first weld seam is identical for every weld case in each experiment and shows the abrupt termination of the laser at full power.

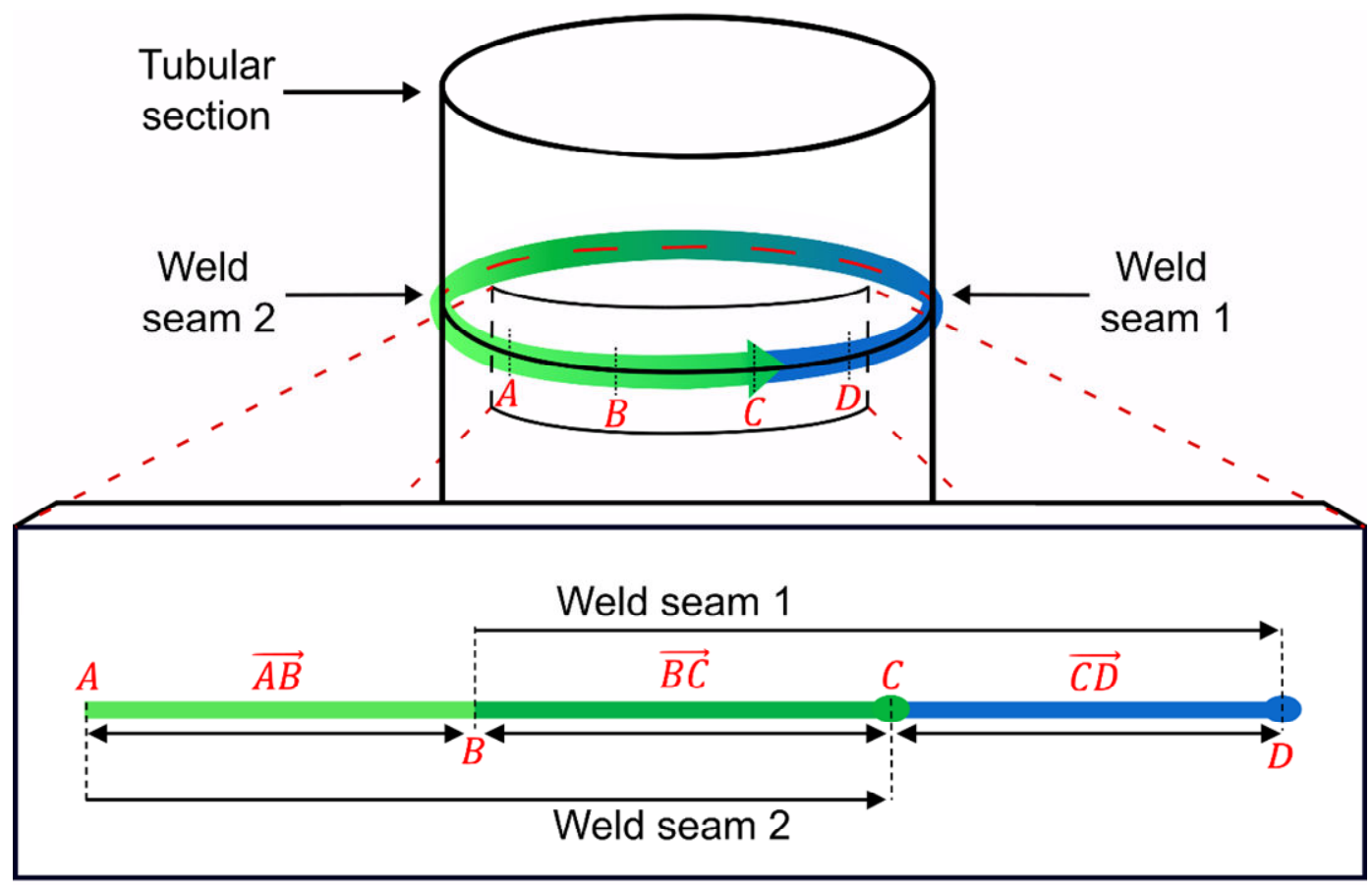


Fig. 1. Illustration of circumferential weld replicated onto a flat plate

\subsection{Experimental setup and materials}

Experiments were conducted using an IPG-YLR fibre laser integrated with a 6-axis Fanuc M700i B45 robot. The wavelength of the laser is $1.06 \mu \mathrm{m}$ and operates at a maximum output power of $8 \mathrm{~kW}$. The laser is transmitted through a fibre with a core diameter of $0.3 \mathrm{~mm}$, a collimation lens with a focal length of $125 \mathrm{~mm}$, and a focusing lens with a focal length of $250 \mathrm{~mm}$. The optical set-up gives a laser beam with a focal spot diameter $(\varnothing)$ of $0.6 \mathrm{~mm}$. The focal spot was positioned on the workpiece surface during welding apart from when laser defocusing was applied.

All welds were conducted in the $2 \mathrm{G}$ horizontal welding position to minimise the effect of gravity on the melt pool, as shown in Fig. 2a. The laser head was tilted by $10^{\circ}$ opposite to the welding direction to avoid back reflection, as shown in Fig. 2b. All weld seams were initiated instantaneously at full power and terminated $30 \mathrm{~mm}$ from the plate edge. No direct shielding gas was used in these experiments to minimise any interactions with the gas plume or melt pool flow. However, in experiment 1, shielding gas was applied in one scenario to understand the impact of gas shielding on the melt pool. $100 \%$ argon shielding gas at $35 \mathrm{l} / \mathrm{min}$ was applied using a cross-jet air knife from the top of the $2 \mathrm{G}$ welding jig. The gas shielding flowed across the top surface of the plate during the second weld seam, covering the weld overlap start-stop region.

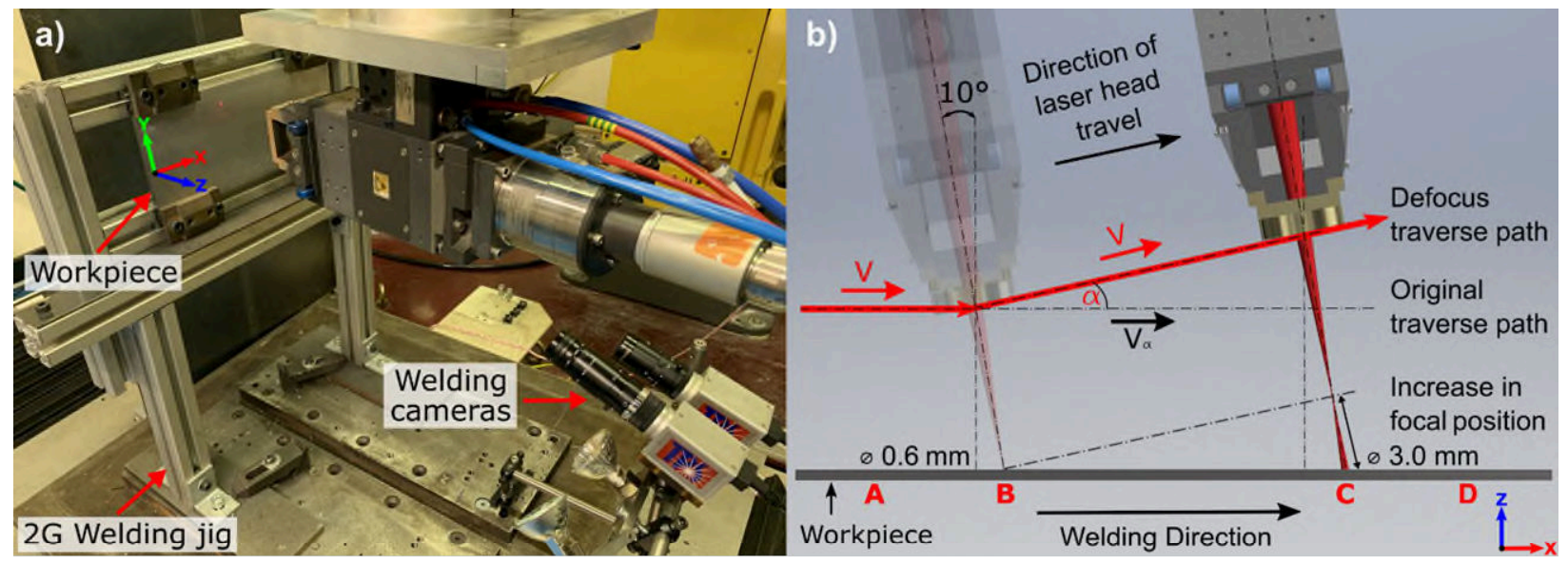

Fig. 2. a) Experimental setup, b) schematic of laser traverse during laser defocusing

Three different batches of $\mathrm{S} 355 \mathrm{~J} 2+\mathrm{N}$ grades structural steel plates were machined to dimensions of $300 \times 180 \times 8 \mathrm{~mm}$ to remove mill scale and cleaned with acetone before welding. The plate and weld bead were cleaned again with acetone after the first weld seam to ensure there was no contamination before the second weld seam was performed. The chemical composition of each plate was tested externally using optical emission spectroscopy analysis, and their composition is shown in Table 1. Micrographs of each plate are shown in Fig. 3 and only plate $L$ was used in experiment 1. X-ray radiographic inspection was carried out on all welded samples to identify any internal defects before metallographic specimens were taken. A $2 \%$ Nital solution was used to etch the metallographic samples after grinding and polishing. A Xiris XVC-1000 weld camera was used in experiment 2 to capture the top surface melt pool behaviour during 
the different laser termination regimes at the weld overlap area. The weld cameras were fixed to the ground below the laser head, and the captured region of interest shows between $30 \mathrm{~mm}$ to $85 \mathrm{~mm}$ after point $\mathrm{B}$.

Table 1. External chemical analysis of $\mathrm{S} 355 \mathrm{~J} 2+\mathrm{N}$ plate variations

\begin{tabular}{cccccccccccccccc}
\hline Plate & $\mathbf{C}$ & $\mathbf{M n}$ & $\mathbf{S i}$ & $\mathbf{S}$ & $\mathbf{P}$ & $\mathbf{C u}$ & $\mathbf{N i}$ & $\mathbf{C r}$ & $\mathbf{M o}$ & $\mathbf{A l}$ & $\mathbf{V}$ & $\mathbf{N b}$ & $\mathbf{T i}$ & $\begin{array}{c}\mathbf{N}^{2} \\
(\mathbf{p p m})\end{array}$ & $\begin{array}{c}\mathbf{O}^{2} \\
\mathbf{p p m})\end{array}$ \\
\hline $\mathrm{L}$ & 0.08 & 0.92 & 0.01 & 0.010 & 0.010 & 0.03 & 0.03 & 0.03 & $<0.01$ & 0.05 & $<0.01$ & 0.03 & 0.02 & 18 & 15 \\
$\mathrm{M}$ & 0.17 & 1.44 & 0.34 & 0.013 & 0.014 & 0.01 & 0.03 & 0.02 & $<0.01$ & 0.02 & $<0.01$ & $<0.01$ & $<0.01$ & 36 & 12 \\
$\mathrm{~N}$ & 0.15 & 1.49 & 0.50 & $<0.005$ & 0.016 & 0.03 & 0.05 & 0.03 & $<0.01$ & 0.04 & $<0.01$ & $<0.01$ & $<0.01$ & 33 & 5 \\
\hline
\end{tabular}
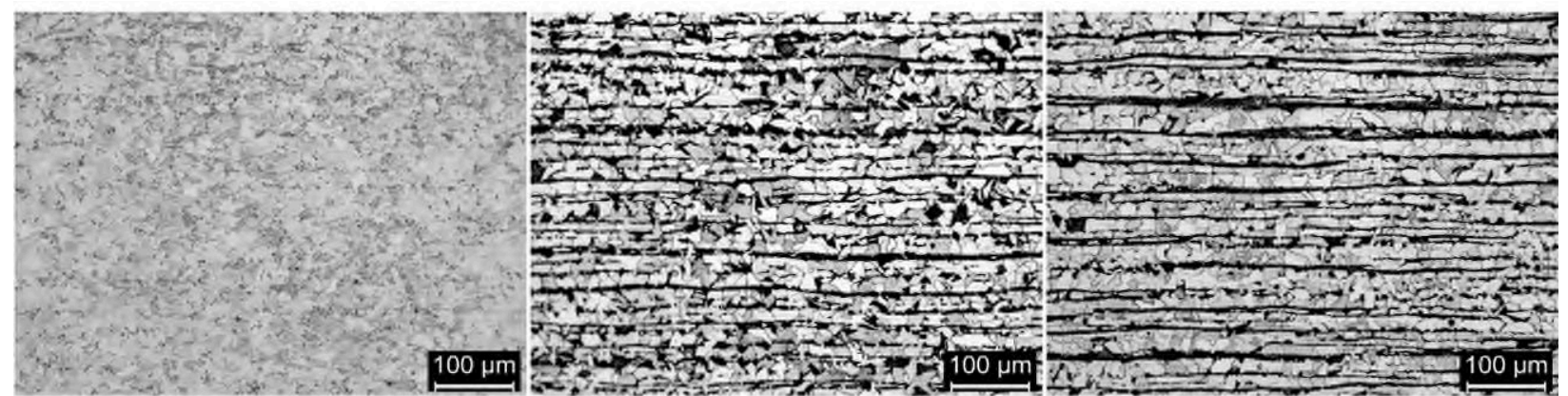

Fig. 3. Macrographs of the three plates of S355J2+N, from left to right: Plate L, Plate M, Plate $N$

\subsection{Weld parameters and termination regimes}

Weld parameters were selected from a series of trial welds, which provided full penetration with uniform top and root surface quality based on visual inspection. Successful trials resulted in a laser power of $3.8 \mathrm{~kW}$ and a welding speed of $0.5 \mathrm{~m} / \mathrm{min}$, which were used in experiment 1. However, an increase of laser power to $5.2 \mathrm{~kW}$ at the same weld speed was used in experiment 2 and is explained later in section 3.2. Note that these parameters would reflect the worst-case scenario conditions as keyhole stability is more challenging to maintain at lower weld speeds due to the large volume of liquid metal.

In experiment 1 , laser termination regimes were applied from point $B$ to point $C$, over an $80 \mathrm{~mm}$ and $40 \mathrm{~mm}$ distance. The difference in weld overlap distances is to compare a low ramp-down or defocus rate $(80 \mathrm{~mm}$ distance), with one that is higher $(40 \mathrm{~mm}$ distance). In experiment 2 , only an $80 \mathrm{~mm}$ overlap distance was applied. The laser power ramp-down regime consists of a linear reduction of laser power from full power at point $B$ to the set termination power at point $C$ for each weld case. The reduction in laser power causes a reduction in applied energy input per unit length. The laser defocusing regime consists of a linear increase of the focal position from point $B$ to point $\mathrm{C}$, by traversing the laser head, as shown in Fig. $2 \mathrm{~b}$, while keeping the laser power constant. As the laser power is kept constant during laser defocusing, the applied heat input is maintained although the power density of the laser changes. The increase in focal position leads to a gradual increase in the laser spot size and reduction in power 
density. The change in welding parameters for each termination regime in each experiment is shown below in Table 2 and Table 3.

The change in laser power density for each termination regime and weld case from points $B$ to $C$ in experiment 1 has been calculated based on a top-hat beam profile, as shown in Fig. 4. Actual values of laser power density will differ during laser defocusing as the beam profile changes from top-hat beam to a gaussian distribution.

Table 2. Welding parameters used in experiment 1

\begin{tabular}{ccc}
\hline Termination regime & Set termination power $(\mathbf{k W})$ & $\begin{array}{c}\text { End laser spot size diameter } \\
(\mathbf{m m})\end{array}$ \\
\hline Laser power ramp-down & $3.8,1,0.5,0$ & 0.6 (same as the spot diameter at \\
the focal position) \\
Laser defocusing
\end{tabular}

Table 3. Welding parameters used in experiment 2

\begin{tabular}{ccc}
\hline Termination regime & Set termination power $(\mathbf{k W})$ & $\begin{array}{c}\text { End laser spot size diameter } \\
(\mathbf{m m})\end{array}$ \\
\hline Laser power ramp-down & 0 & 0.6 (same as the spot diameter at \\
the focal position) \\
Laser defocusing
\end{tabular}
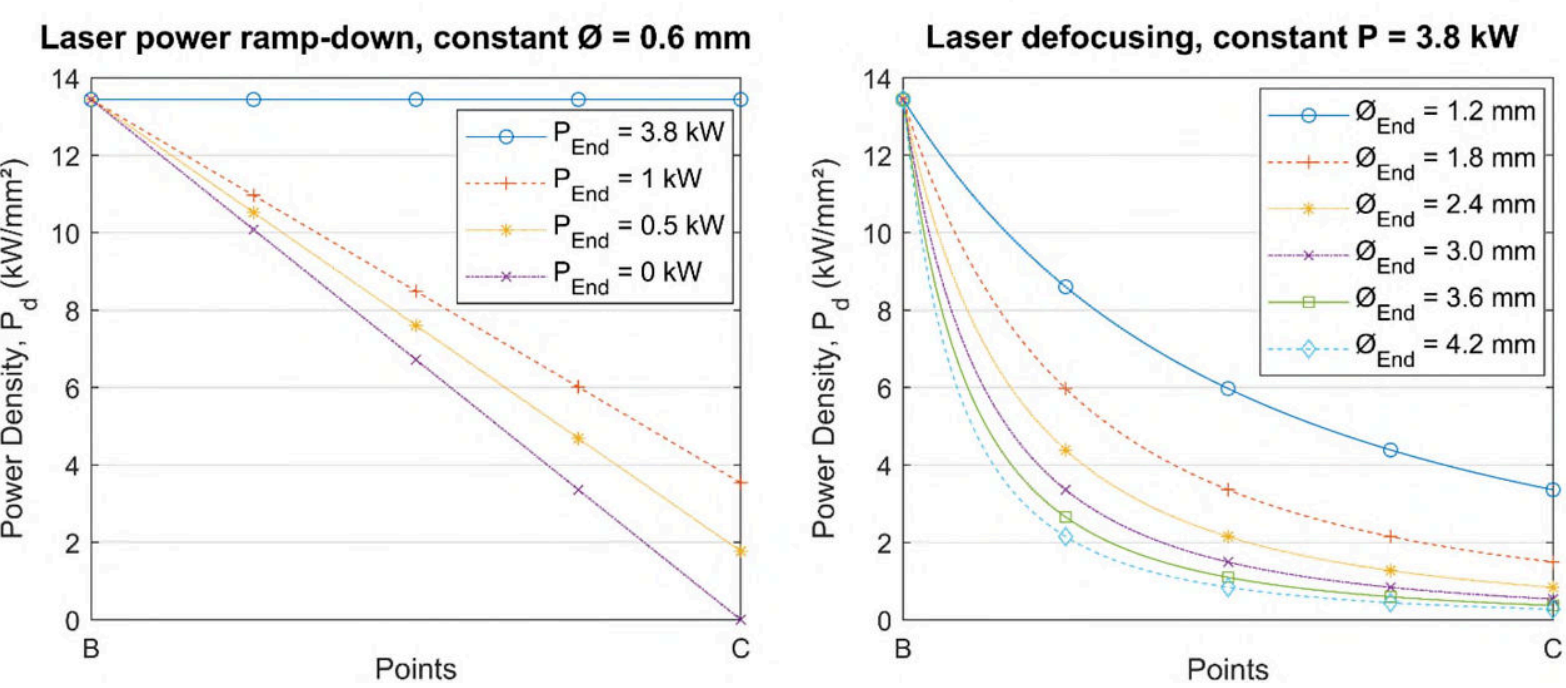

Fig. 4. Change of laser power density during each laser termination regime for experiment 1

\section{Results and discussion}

\subsection{Experiment 1: effect of different laser termination regimes}

In experiment 1, all weld cases were conducted using the range of parameters shown in Table 2 and performed on plate L only. Fig. 5 a shows the weld top surface and an X-ray image of the reference weld, highlighting the areas where samples were taken, and 
where internal defects occurred. Fig. 5b shows longitudinal macrographs of each initiation and termination point, and cross-sectional macrographs in-between each point. As previously mentioned, parameters were kept constant apart from the changes at the weld overlap. Therefore, all weld areas outside of the weld overlap area for each weld case are identical to the reference weld.

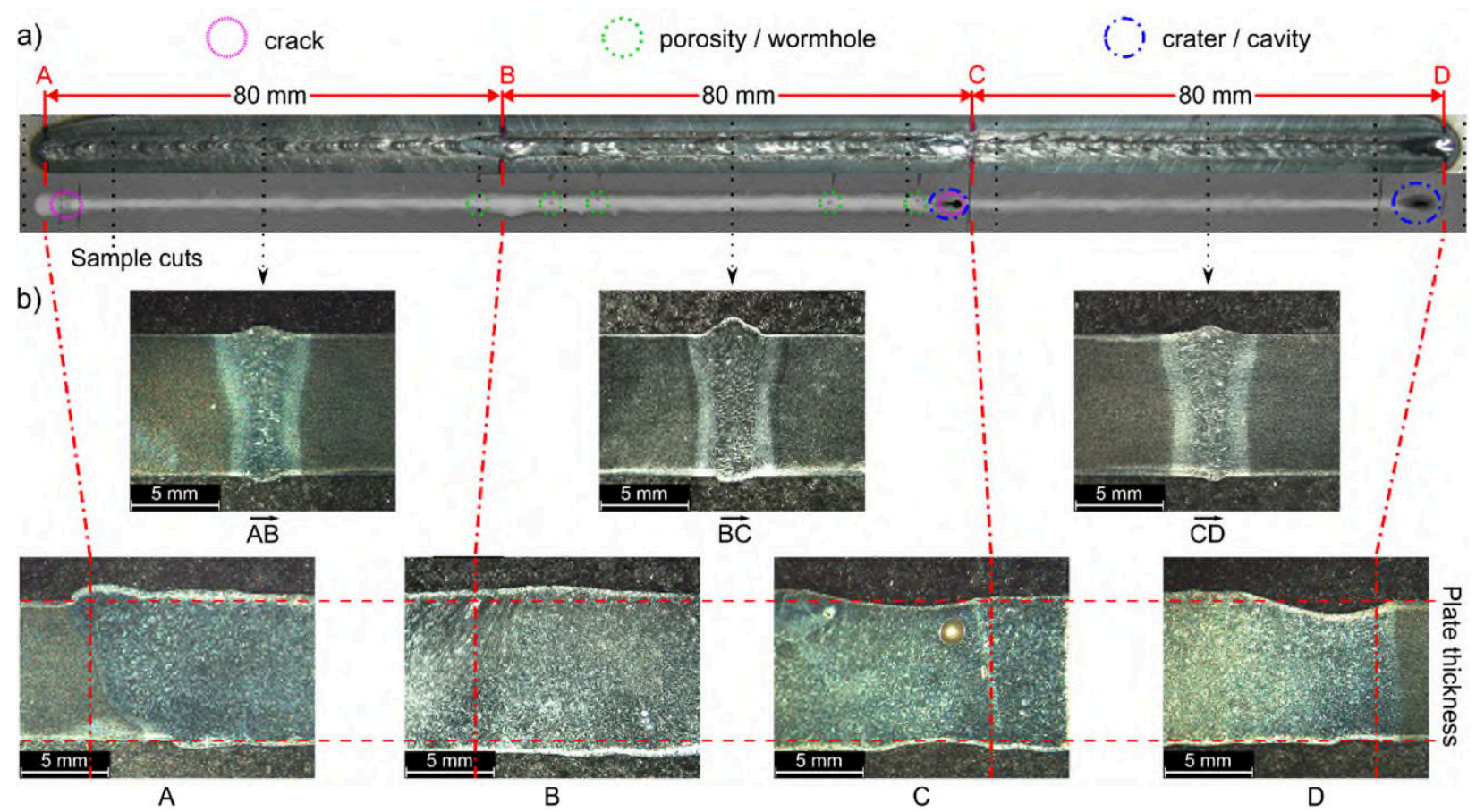

Fig. 5. Reference weld of abrupt laser termination at weld overlap a) weld top surface and X-ray image, b) longitudinal and cross-sectional macrographs at specific locations

From Fig. 5, excess weld reinforcement and weld width at point $A$ and point $B$, due to the laser initiation and flow of material, can be seen. In several weld cases, solidification cracking was observed just after laser initiation (point $A$ ) as can be seen from the X-ray images. At point $B$, where the laser initiation of weld seam 1 was overlapped by weld seam 2, there is no indication of solidification cracking. However, small amounts of porosity are present either side of point $B$. The formation of the cracks at the initiation point $A$ can be attributed to the shrinkage stresses during solidification from the tapering, partially penetrating weld profile. When welding over an initiation point (point $B)$, the re-melting of the weld is allowing the molten metal to repair any cracks that may have formed. When compared with the tapering, partially penetrated weld profile seen at point $A$, the more uniform weld profile at point $B$, would lead to less shrinkage stresses to occur.

Point $C$ and point $D$, where the laser terminates abruptly, show a depression in the form of a surface crater at the top and a slightly smaller crater at the root. The craters at the termination points is a result of the rapid solidification of the laser keyhole before enough material can fill the cavity. A large pore is observed at point $C$, where the laser 
terminates abruptly at the weld overlap, which is a typical defect of laser keyhole collapse, gas entrapment and rapid solidification. Steady-state weld cross-sections $\overrightarrow{\mathrm{AB}}$ and $\overrightarrow{\mathrm{CD}}$ are identical and represent the welds that do not intersect in a circumferential weld seam. In some instances, small amounts of porosity are present throughout the welds as observed from the X-ray images as the weld parameters were not fully optimised. The weld overlap cross-section $\overrightarrow{\mathrm{BC}}$ for the reference weld is like $\overrightarrow{\mathrm{AB}}$ and $\overrightarrow{\mathrm{CD}}$ apart from the slight increase in weld reinforcement and porosity formation due to welding on top of a previous weld. Welding on top of a previous weld may lead to the incorporation of more surface-active elements and surface oxides, resulting in a compositional change. These factors would change the melt pool flow pattern and, therefore, result in a slightly different weld profile and melt pool flow behaviour.

The weld top surface photographs and X-ray images of the weld overlaps (point B to point $C \pm 10 \mathrm{~mm}$ from each side) for each termination regime is shown in Fig. 6 and Fig. 7. As previously mentioned, no cracks can be seen at initiation point $B$ for all weld cases regardless of the termination regime applied. An increase in weld reinforcement and weld width is observed at point $B$, and in some cases, the formation of porosity is visible as was seen previously in the reference weld shown in Fig. 5. The weld width of the weld overlap region varies depending on the termination regime applied. For the laser power ramp-down regime, the weld width decreases as the laser power is reduced, and the opposite occurs during laser defocusing due to the increasing laser spot size. This difference will also change the thermal cycle and cooling rate experienced at the weld overlap. The difference in the weld profile between the two termination regimes is due to the change in applied laser power density and heat input. At the laser termination point $C$ for both termination regimes, surface craters and cavities may still be present depending on the laser termination parameters. The severity of these defects is significantly reduced when the laser power is ramped down to $0 \mathrm{~kW}$ at the termination point in the laser power ramp-down regime, or the laser is defocused above an end laser spot size diameter of $3 \mathrm{~mm}$ in the laser defocusing regime.

In the laser power ramp-down regime, small craters are present at the termination point when the laser power is gradually ramped down from full power to $1 \mathrm{~kW}$ and $0.5 \mathrm{~kW}$ before switching off the laser power. For both weld overlap distances, craters were observed as highlighted in the X-ray images in Fig. 6 . The presence of porosity occurring in the weld overlap area was found to be reduced when compared to the reference weld in Fig. 5 despite partial penetration welding. The lack of porosity and root defects, such as root sagging, shows that successful keyhole closure and a smooth transition from full penetration towards partial penetration was achieved without significant issues. However, when the laser power is ramped down from full power to 0 $\mathrm{kW}$ over an $80 \mathrm{~mm}$ overlap distance before terminating, a small cluster of porosity prior to the laser termination point $C$ was observed. In the $40 \mathrm{~mm}$ overlap distance weld 
case, no porosity was observed as can be seen in Fig. 6 . The presence of the cluster porosity near the termination point in the $80 \mathrm{~mm}$ overlap distance weld case demonstrates the complexity of the process. There is an optimum balance between the reduction of the keyhole depth and the solidification of the molten metal. If the rampdown rate is too high, as is the case for rapid termination of the laser and short overlap distances, the abrupt drop in vapour recoil pressure can lead to keyhole collapse. In the $80 \mathrm{~mm}$ overlap case, the ramp-down rate is too slow, which increases the likelihood of liquid-vapour instabilities and more gases dissolving in the melt pool.

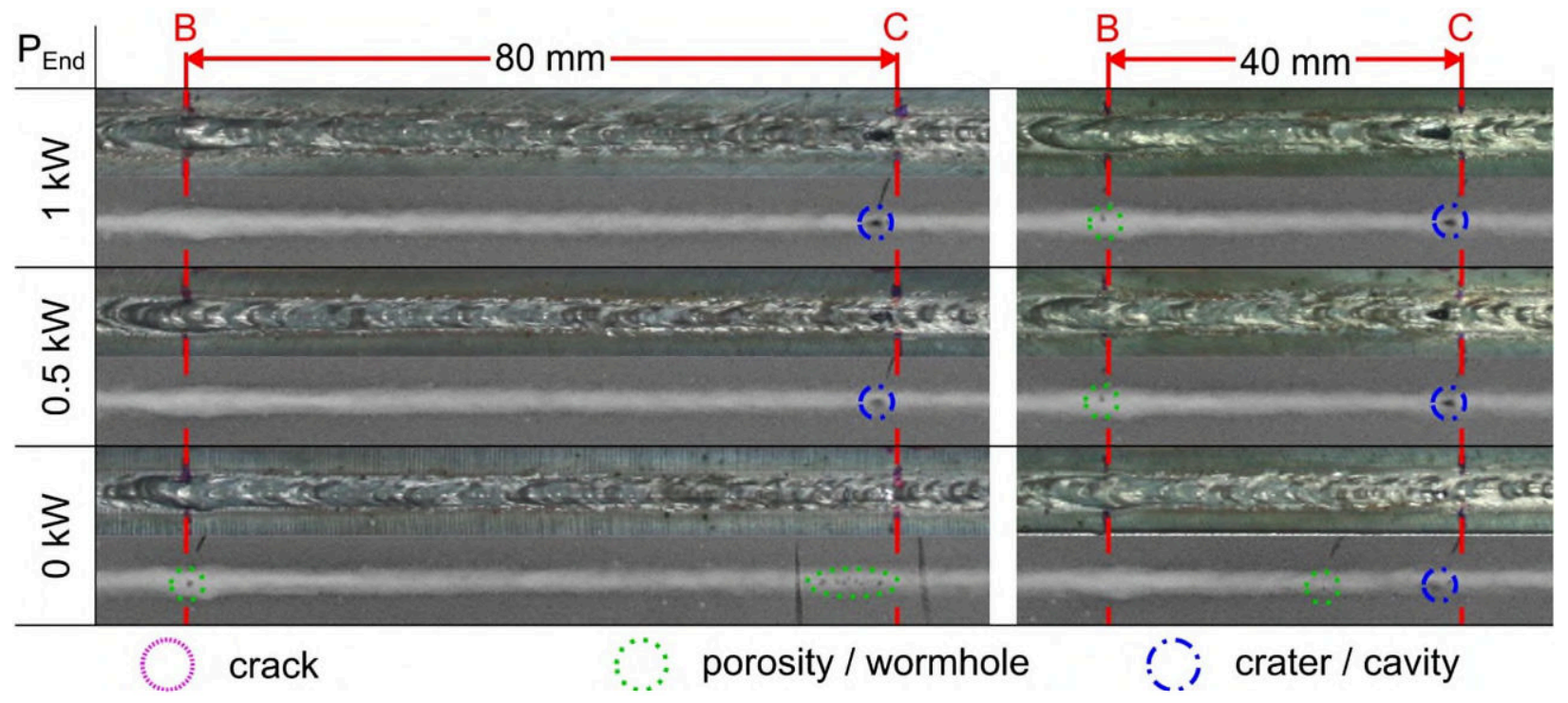

Fig. 6. Weld top surface and X-ray images of weld overlap using laser power ramp-down termination regime

In the laser defocusing regime, weld craters were present below an end laser spot size diameter of $2.4 \mathrm{~mm}$ as shown by the weld surface and X-ray images in Fig. 7. When the laser is defocused to an end laser spot size diameter of $3 \mathrm{~mm}$ and above however, an unusual phenomenon occurs. At a certain distance of laser defocusing, the weld surface becomes rippled and a significant amount of porosity clusters or wormholes for both weld overlap distances is present. The surface ripples and porosity clusters only occurred when the laser spot size diameter reached $2.4-2.5 \mathrm{~mm}$ and above based from calculations of the laser defocusing distance. 


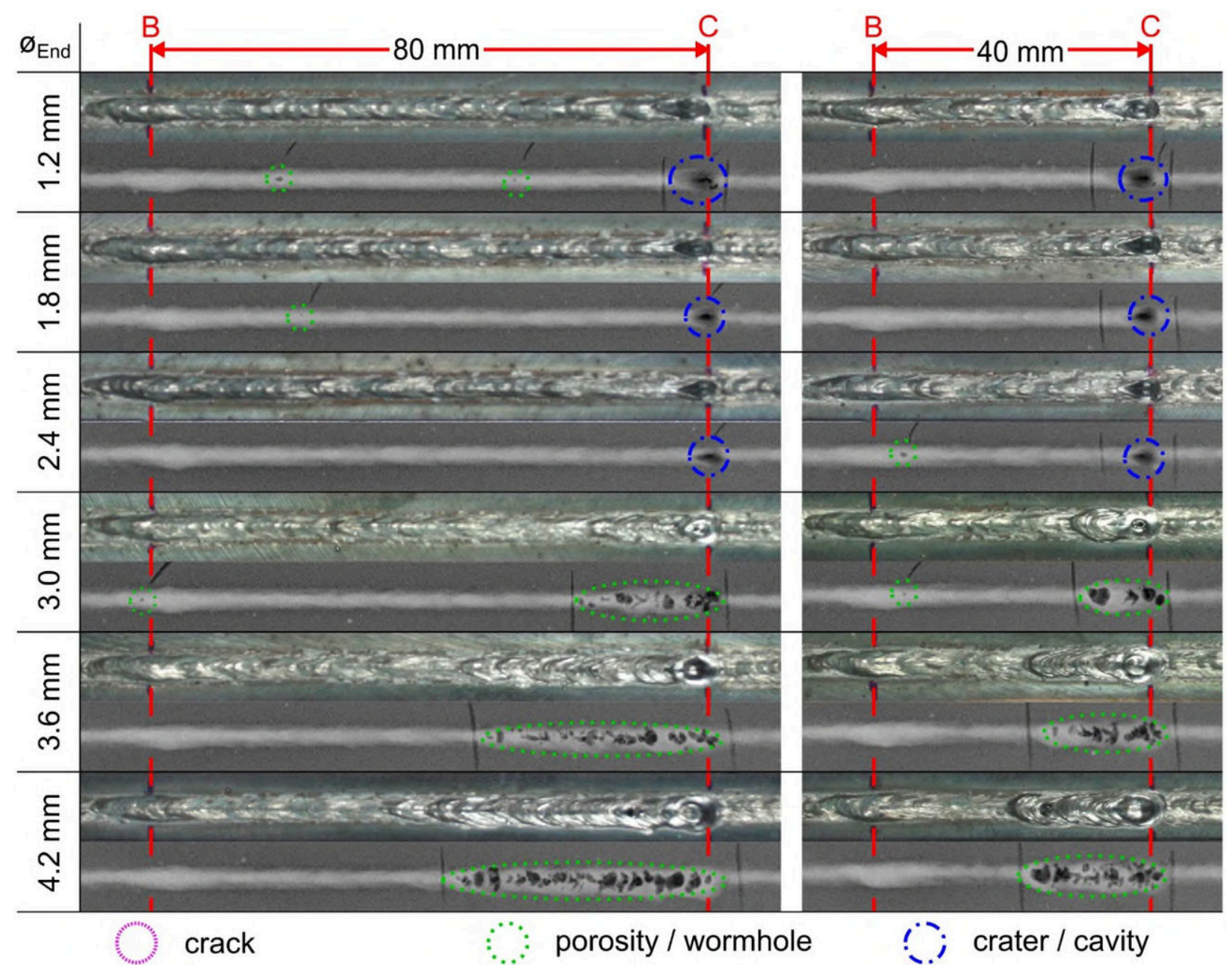

Fig. 7. Weld top surface and X-ray images of weld overlap using laser defocusing termination regime

Top surface photograph and longitudinal macrographs of $40 \mathrm{~mm}$ weld overlap from each termination regime are presented in Fig. 8 showing the through-thickness weld profile along the centreline of the weld. There is a comparable difference between the two laser termination regimes when the penetration depth is concerned. In the laser power ramp-down regime, the penetration decreases linearly with the change of laser power and laser power density. In the laser defocusing regime, however, the penetration decreases following a parabolic trend until it stabilises at a certain penetration depth despite the continued increase in the laser spot size diameter. The change in penetration depth for both laser termination regimes correlates with the change in laser power density, as shown in Fig. 4. In all weld cases for either termination regime, the transition from full penetration to partial penetration welding does not cause any defects at the root, such as root sagging that was observed in studies carried out by Gook et al. [12]. The size and depth of the craters and cavities present at point $\mathrm{C}$ can be seen in more detail in Fig. $8 \mathrm{a}$, and Fig. $8 \mathrm{~b}$. As the set termination power is reduced in laser power ramp-down termination regime, the size 
and depth of the crater also reduce. The same is also true in the laser defocusing termination regime when the laser terminates at a larger end laser spot size diameter.

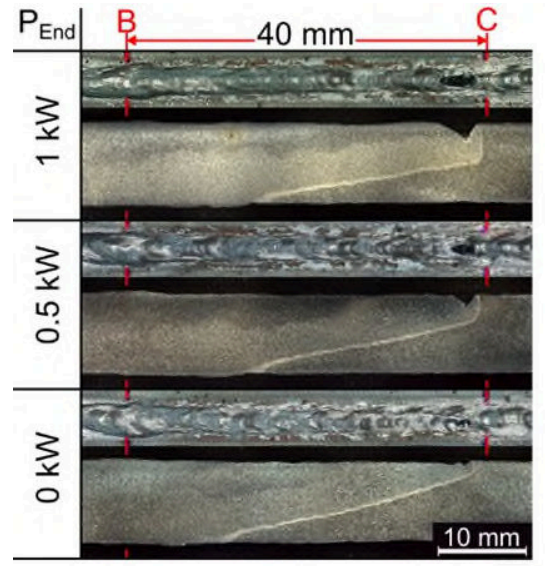

a) Laser power ramp-down

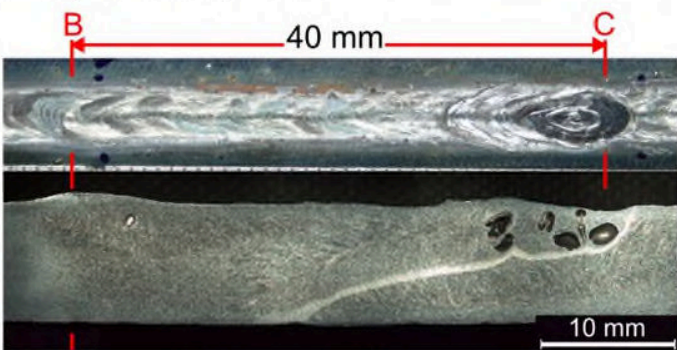

without shielding gas
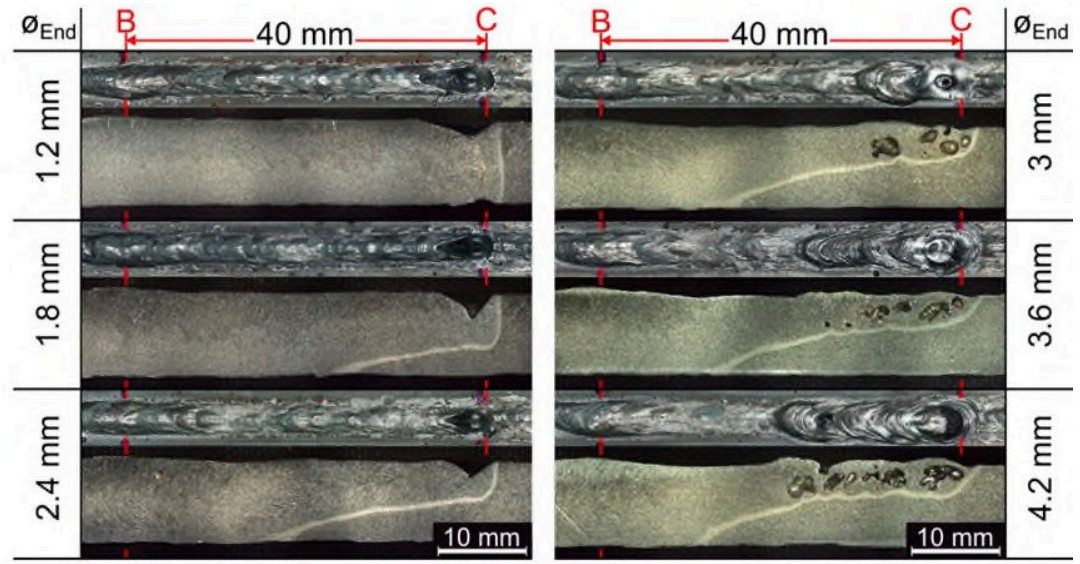

b) Laser defocusing

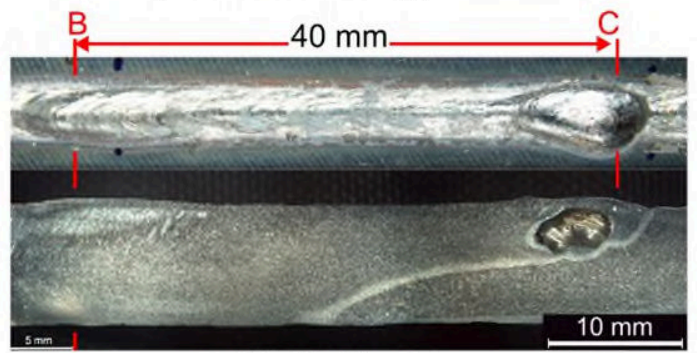

with shielding gas

c) Laser defocusing to $\emptyset_{\mathrm{End}}=3 \mathrm{~mm}$, without and with shielding gas

Fig. 8. Weld top surface and longitudinal macrographs of weld overlap over $\mathbf{4 0} \mathbf{m m}$, a) laser power ramp-down, b) laser defocusing, c) laser defocus to $3 \mathrm{~mm}$ without and with shielding gas

The large porosity clusters or wormholes as was shown previously by the X-ray images in Fig. 7 is now shown more clearly in Fig. 8b. This phenomenon only occurs at a certain distance of defocusing as previously mentioned, where the laser spot size diameter reached $2.4-2.5 \mathrm{~mm}$ and above. The location of the porosity clusters and surface ripples also coincide with the stabilisation of the penetration depth as can be seen from the weld profile. The calculated laser power density for a laser spot size diameter of $2.4 \mathrm{~mm}$ is approximately $0.84 \mathrm{~kW} / \mathrm{mm}^{2}$. At this point, the weld profile is no longer in keyhole mode welding, but closer to conduction mode welding as the weld width and penetration depths are similar. The larger surface area of the melt pool due to the increasing laser spot size diameter can lead to increase interaction between the melt pool surface and the atmosphere. This interaction can lead to an increase in gas entrapment, oxygen ingress, melt pool turbulence and melt pool instability.

Therefore, a brief investigation into the effect of shielding gas on the porosity cluster formation was conducted. One weld case of laser defocusing to a $3 \mathrm{~mm}$ end laser spot size diameter was repeated with and without shielding gas across the weld overlap area. The result of shielding gas on the weld overlap during laser defocusing is shown 
in Fig. 8c. The repeated weld without shielding gas shown in Fig. 8c is identical to the weld case in Fig. 8b in regards to the weld appearance and porosity cluster formation and location. When the cross-jet shielding gas is applied, the top surface appearance is much smoother and without ripples as compared to the weld case without shielding gas. However, instead of porosity clusters, the formation of a significantly large pore is present instead at the termination point $\mathrm{C}$. The rippled weld surface is an indication of the rather turbulent melt pool flow and behaviour, which can lead to gas entrapment and melt pool instability during solidification and this correlates with the porosity cluster formation. The shielding gas can reduce the interaction of the melt pool with the atmosphere and surface-active elements like oxygen. It can also reduce the surface temperature of the melt pool. These effects can reduce the turbulence of the melt pool during laser defocusing, which minimises both gas entrapment and melt pool instability.

The formation of the large pore observed at the termination point in the repeated weld with shielding gas applied could be due to two possibilities. Firstly, when there is turbulent flow, air bubbles and entrapped gases are mixed and distributed across the whole melt pool in the form of porosity clusters as observed. However, when the flow is less turbulent, the entrapped gases can coagulate to form a larger bubble. The second possibility is that the large pore formation is due to shielding gas entrapment during laser termination and solidification. Further investigations are required to determine the exact cause of the large pore formation that occurred under these circumstances.

In summary, the results from these set of experiments show that the laser defocusing termination regime is more prone to porosity formation when compared with the laser power ramp-down termination regime. During the laser power ramp-down termination regime, the applied heat was continually reducing with the laser power, resulting in a gradual reduction of the melt pool size and keyhole depth. In contrast, during laser defocusing the applied heat was maintained, increasing the melt pool size while the keyhole depth reduces. The larger melt pool size increases the interaction of the melt pool with the atmosphere and can lead to increased melt pool instability. Both these phenomena can lead to increase oxygen ingress from the environment and in the absence of deoxidising elements, result in significant gas entrapment leading to the formation of porosity clusters.

\subsection{Experiment 2: effect of plate composition during different laser termination regimes on weld start-stop region}

Experiment 2 was conducted to understand the significance of deoxidising elements on gas entrapment during application of different laser termination regimes observed previously in experiment 1. Different batches of S355J2+N grade structural steel plates and a range of laser parameters were studied, as shown in Table 1 and Table 3, respectively. Three welds from experiment 1 were repeated on plate $L$ with identical 
parameters for direct comparison. As shown in Table 1, the only differences between the plates is that plate $L$ has a lower percentage of carbon, manganese and silicon content. Both manganese and silicon are deoxidisers used during the manufacturing process of steels; hence, the difference of oxygen is proportional to the difference in manganese and silicon. The melt pool flow behaviour is, therefore, likely to be affected as the ingress of oxygen from the atmosphere when welding is likely to be larger in plate $L$ due to the lower concentration of deoxidisers. The percentage of manganese and silicon can be seen to increase in order from plate batch $L$ to $N$.

Fig. 9 shows, the cross-sectional macrographs from the reference welds of each plate between points $A$ and $B$. As can be seen, a loss of penetration can be observed on plates $\mathrm{M}$ and $\mathrm{N}$ when compared with plate $\mathrm{L}$ despite using identical welding parameters. The penetration depth can be seen to decrease from plate $L$ to $N$ and correlates with the increase in manganese and silicon content. An increase of laser power by $37 \%$; from $3.8 \mathrm{~kW}$ to $5.2 \mathrm{~kW}$, at the same laser spot size and welding speed was necessary to achieve full penetration with good weld surface quality and without defects, such as undercuts, root sagging and humping. The difference in penetration depth can only be associated with the effect of carbon, manganese, or silicon content on the melt pool. These elements were the only ones that had significant variation in the chemical composition between the three plates investigated. As previously mentioned, both manganese and silicon are deoxidisers, and due to the lower concentration of these elements in plate $\mathrm{L}$, there is the potential of oxygen ingress from the atmosphere. Oxygen concentration above a certain percentage would lead to a positive temperature gradient of surface tension and increase the fluidity of the melt pool. The changes in Marangoni flow and surface tension effects can lead to an increase in penetration depth as was experienced in the welds on plate L. However, some authors considered the effects of Marangoni flow to be negligible in laser keyhole welding $[18,19]$. Instead, the authors attributed the increase in penetration to the possibility of carbon monoxide formation owing to the higher amounts of dissolved oxygen in the melt pool. The increase in carbon monoxide can lead to increased pressure within the keyhole and therefore, increased penetration.

On the other hand, the higher concentrations of manganese and silicon in plates $\mathrm{M}$ and $\mathrm{N}$ promotes slag formation in the form of manganese oxide and silicon dioxide. The slag formation protects the melt pool from oxygen ingress but also affects the surface tension. Therefore, the opposite behaviour for both Marangoni flow and carbon monoxide formation occurs, and a reduction in penetration depth is observed. 


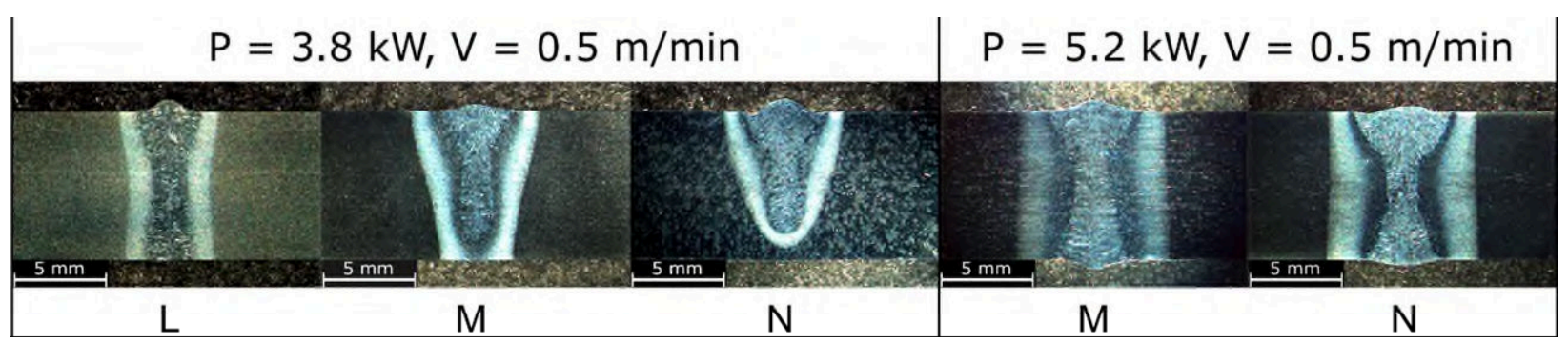

Fig. 9. Reference welds on different plates of S355J2+N showing difference in penetration depth

The penetration depth was not the only difference when it came to laser welding on the different composition plates of S355J2+N. Weld surface, X-ray images and longitudinal macrographs of the laser power ramp-down termination regime over an $80 \mathrm{~mm}$ distance on plates $\mathrm{M}$ and $\mathrm{N}$ are shown in Fig. 10. In the partial penetration welds, when a laser power of $3.8 \mathrm{~kW}$ was used with plates $\mathrm{M}$ and $\mathrm{N}$, no porosity was observed near the termination point $\mathrm{C}$, when compared with the results in experiment 1 shown by the X-ray images in Fig. 6. In the case of full penetration welds that were achieved with a laser power of $5.2 \mathrm{~kW}$ on plates $\mathrm{M}$ and $\mathrm{N}$, there were also no defects, such as porosity, in the weld overlap area or the termination point $\mathrm{C}$, as shown in Fig. 10. Unfortunately, during the laser power ramp-down on plate $\mathrm{M}$, a large surface crater formed due to keyhole collapse in the middle of the weld overlap and solidifying.

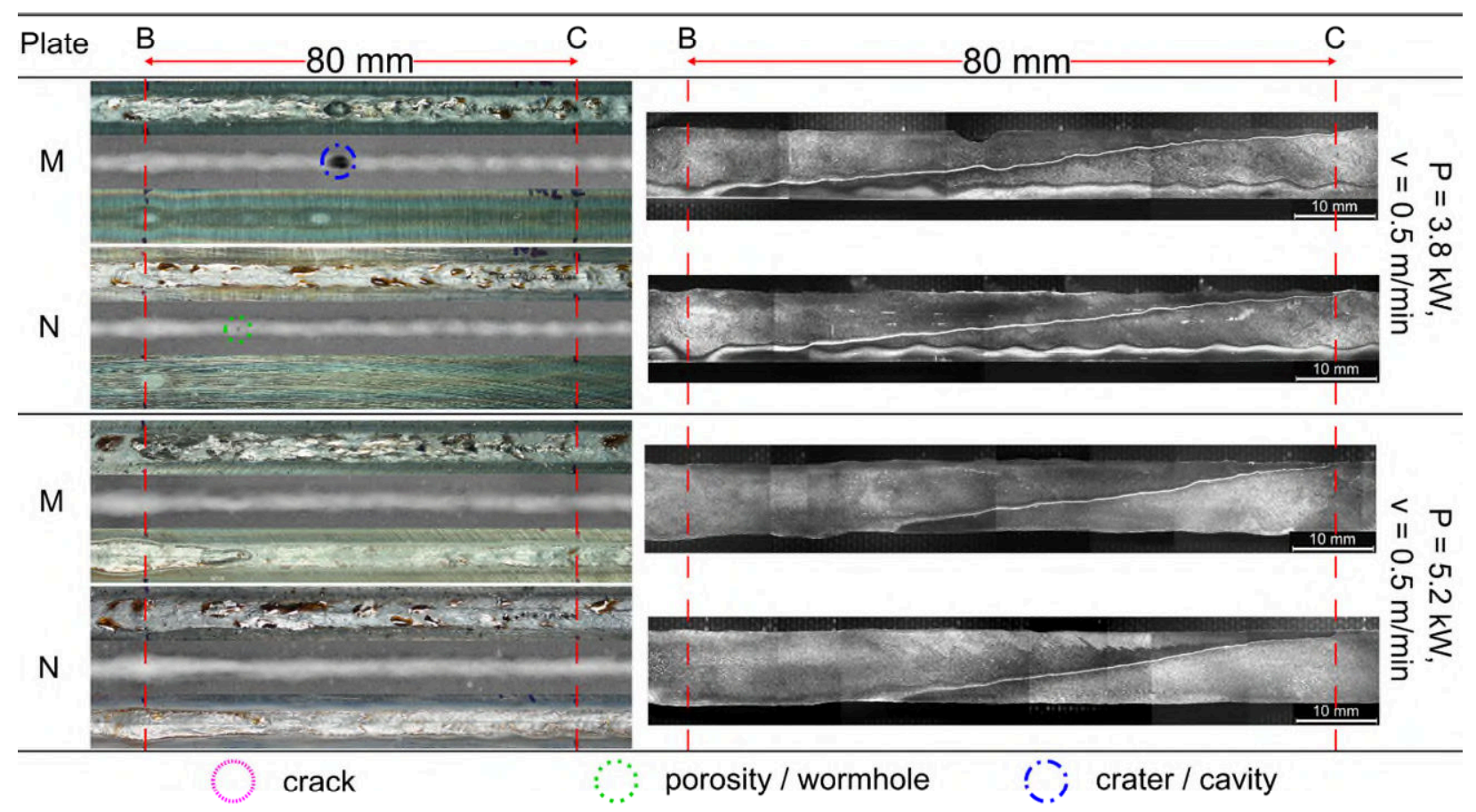

Fig. 10. Weld top surface, X-ray images, weld root surface and longitudinal macrographs of weld overlap using laser power ramp-down termination regime on different plates of $5355 \mathrm{~J} 2+\mathrm{N}$

As shown in Fig. 11, there is also a noticeable difference in plate composition on the weld surface profile and porosity cluster formation during the laser defocus termination 
regime. Laser defocusing to an end laser spot size diameter of $4.2 \mathrm{~mm}$ over an $80 \mathrm{~mm}$ distance on plate L, shown previously in experiment 1 in Fig. 7 , was repeated and used for direct comparison. The porosity formation in plate $L$ corresponds well with the different melt flow behaviour, as shown by the rippled surface, which indicates melt pool instability as previously explained in experiment 1 . When using the same laser defocusing parameters on plates $\mathrm{M}$ and $\mathrm{N}$, partial penetration was observed as discussed previously; however, no porosity cluster formation or surface ripple behaviour was present. In the case of full penetration welds on plates $\mathrm{M}$ and $\mathrm{N}$, there were no signs of porosity cluster formation or surface ripple behaviour either. The results show that plate $\mathrm{M}$ and $\mathrm{N}$ do not exhibit this melt pool instability behaviour that was observed in plate $L$ and discussed previously in experiment 1 .

There is also a noticeable effect of manganese and silicon content on slag formation. Plate $L$ shows no observable slag formation on the weld surface. However, a significant amount of slag is present on the weld surface of plate $\mathrm{M}$ and $\mathrm{N}$. The $\mathrm{X}$-ray images show the presence of small slag patches and oxide inclusions at the edge of the weld bead, which has been highlighted as porosity in Fig. 11. The slag formation at either side of the weld bead from plates $\mathrm{M}$ and $\mathrm{N}$ also coincides with the outward flow direction of the melt pool as was observed by Ahsan et al. [16].

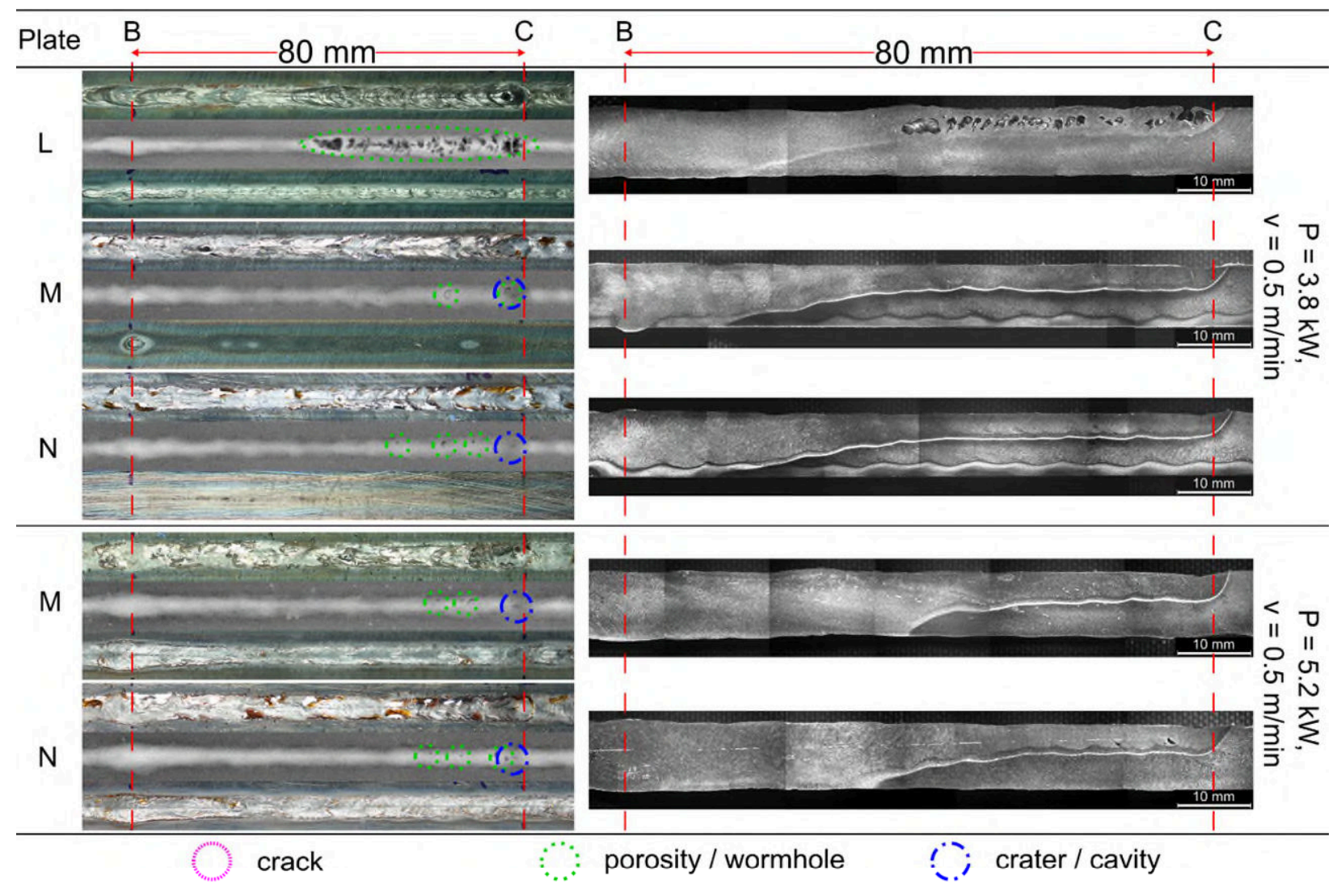


Fig. 11. Weld top surface, $X$-ray images, weld root surface and longitudinal macrographs of weld overlap using laser defocusing termination regime on different plates of $S 355 \mathrm{~J} 2+\mathrm{N}$

Analysis of the video image footage also shows the difference in weld melt pool behaviour of the different plates during the laser defocusing termination regime, as depicted by the compiled video frames in Fig. 12. Both the melt pool and weld plume has been highlighted for each weld case and at varying time intervals. The video of laser defocusing on plate $L$ showed that the melt pool was longer and more turbulent in appearance at a certain distance of laser defocusing. The turbulence of the melt pool correlates well with the location of the surface ripples and porosity cluster formation. As can be seen, when comparing the melt pool and weld plume from each plate, there is a significant difference around $3 \mathrm{~s}$ into the video. In plate $\mathrm{L}$, the weld plume is tall and constricted, whereas, in plate $\mathrm{M}$ and $\mathrm{N}$, the weld plume appears to become shallower and more dispersed. At $5.1 \mathrm{~s}$ into the video, which is $1 \mathrm{~s}$ before the laser is terminated, the weld plume in plate $L$ is still tall, and the melt pool still turbulent with lots of movement indicating that significant interactions occur within the melt pool. On the other hand, videos of laser defocusing on plates $\mathrm{M}$ and $\mathrm{N}$ showed that the melt pool and weld plume is stable throughout the laser defocusing termination regime and weld overlap.

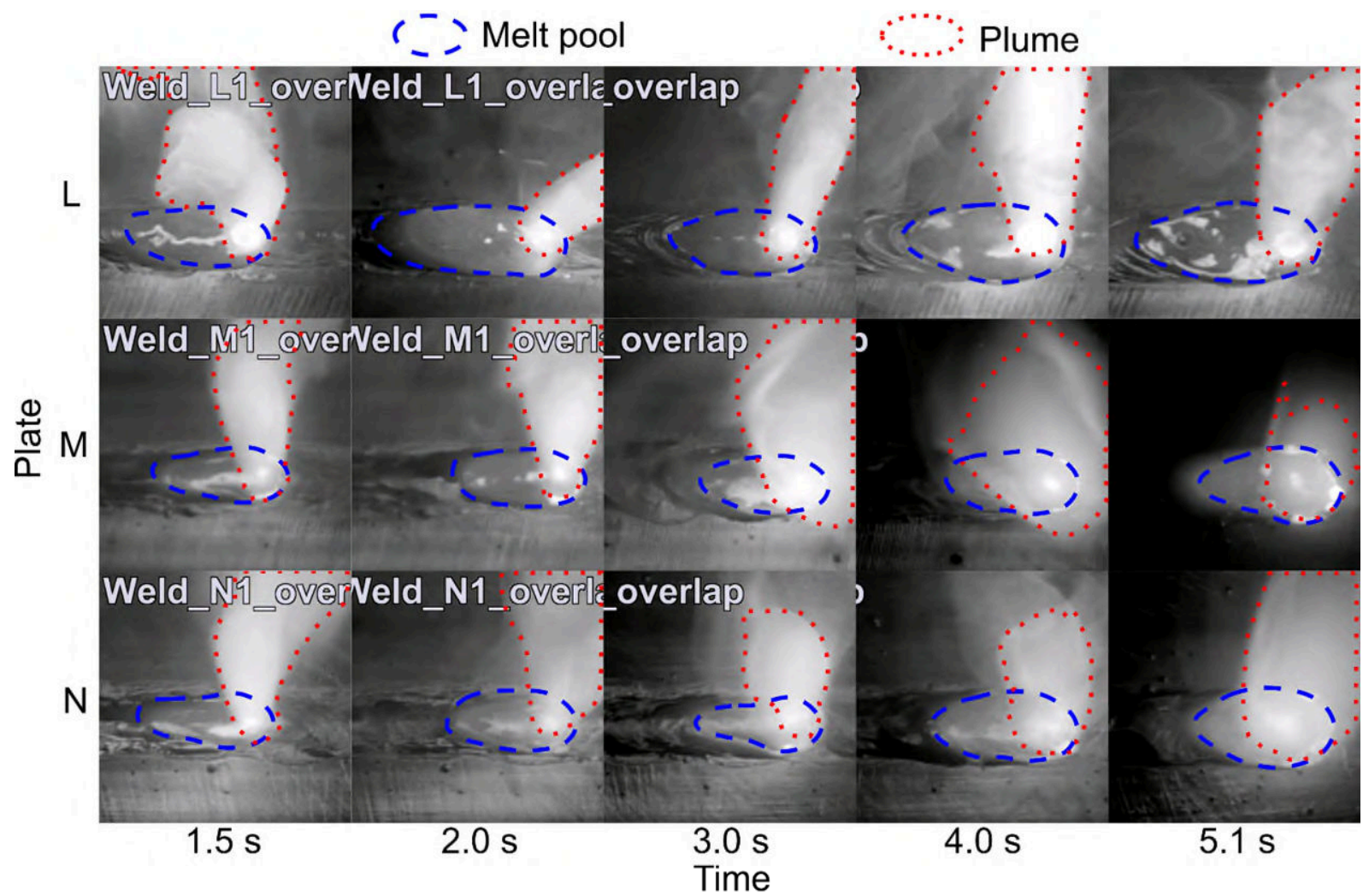

Fig. 12. Video frame close-up during laser defocusing termination regime of different plates of S355J2+N at varying time intervals with melt pool and weld plume highlighted

Fig. 13 shows further video frames around $5.1 \mathrm{~s}$ of the laser defocusing on plate $\mathrm{L}$ aligned with the weld top surface, X-ray image and longitudinal macrograph. The video 
frames show that the melt pool fluctuates from convex to concave and collapses with a small spherical depression in the melt pool surface. The location of the spherical depression is in alignment with the porosity formation, as highlighted. These fluctuations began at the same time as the surface ripples and show that the collapse of the melt pool causes the melt pool turbulence, instability, and surface ripples. It appears that formed gases within the melt pool are trying to escape, and in doing so, affecting the surface tension, and causing the melt pool to collapse when they break through the liquid surface. The escaping gases, coupled with the collapse of the melt pool, can promote further gas entrapment and porosity formation due to melt pool instability.

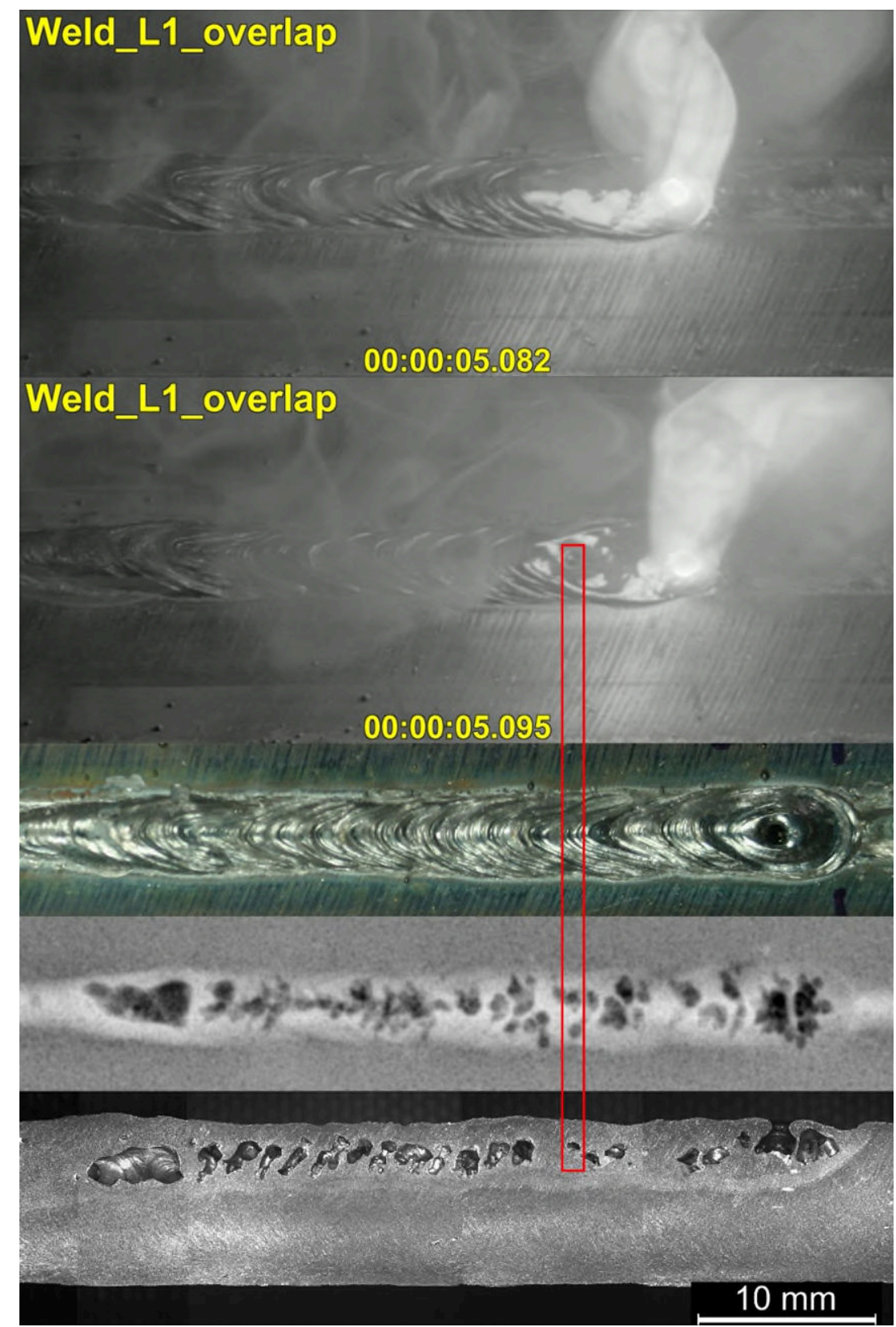


Fig. 13. Video frame comparison with plate top surface, X-ray image and macrograph, highlighting melt pool instability and porosity formation in the laser defocus termination on plate $L$

The difference of the melt pool flow and weld plume behaviour correlates well with the chemical composition of the different plates of $\mathrm{S} 355 \mathrm{~J} 2+\mathrm{N}$ and the formation of porosity clusters during the laser defocusing termination regime. Low alloy carbon steel plates with higher manganese and silicon content can reduce the viscosity of the molten metal and the oxygen ingress from the atmosphere. These phenomena influence laser penetration during steady-state welding and melt pool stability during laser termination. The effect of this phenomenon is more severe in the laser defocusing termination regime compared with laser power ramp-down termination regime due to the increased melt pool size and higher applied heat. The higher manganese and silicon content also promote slag formation that reduces the interaction of the melt pool surface with oxygen from the atmosphere, and the surface tension of the melt pool as well.

A balance between the keyhole depth, melt pool size and melt pool flow is necessary to avoid defect formation during laser termination. If the melt pool size is reduced simultaneously with the reduction in keyhole depth, as occurs during the laser power ramp-down termination regime, then significantly fewer defects are formed. However, if the melt pool is large and keyhole shallow, as is the case during the laser defocusing termination regime, the possibility of melt pool interaction with the atmosphere and melt pool instability is increased. The balance between the melt pool size and keyhole depth also depends on the liquid properties of the metal, melt pool flow and surface tension effect. These factors are influenced by the percentage of deoxidisers and surface-active elements present within an alloy.

For laser keyhole welding of low carbon steels, it is recommended to use steels with a higher proportion of deoxidisers to prevent defect formation, such as porosity, especially when laser termination within a workpiece is necessary. Both termination regimes enable successful laser termination without defects, but laser defocusing does not change the cooling rate and penetration depth as rapidly as with laser power rampdown. However, laser defocusing can expose the melt pool to oxidation from the atmosphere due to the increased melt pool area, which can affect the melt pool flow and stability.

\section{Conclusion}

The following conclusions were derived from this study:

- Successful mitigation of laser termination related defects, such as porosity, cavities, and craters, associated with the abrupt termination of the laser source is possible by the progressive reduction of the laser power density. Reduction of the laser power density can be achieved by either reducing the laser power or defocusing of the laser spot size diameter. 
- Both the termination mechanisms studied are capable of successful keyhole closure through transitioning from full penetration, laser keyhole mode welding, towards partial penetration welding. The two termination regimes give two distinct weld profiles that correlate with the change in laser power density and reducing penetration depth.

- Laser power ramp-down is easier to apply but can result in an abrupt change to the applied heat and weld profile when leaving full penetration. Whereas, laser defocusing maintains the heat applied and result in a smoother keyhole closure and weld profile transition, however, if done incorrectly can induce melt pool instability and porosity formation.

- The increase in melt pool size and applied heat during laser defocusing can lead to increased melt pool dimensions, and thereby, melt pool instability and interaction with the atmosphere.

- The same grades of steel, but with different composition due to the deoxidising practice followed during steelmaking, would have a profound influence on the laser termination zone, and this phenomenon is exacerbated during laser defocusing.

\section{Declaration of competing interest}

The authors declare that they have no known competing financial interests or personal relationships that could have appeared to influence the work reported in this paper.

\section{Acknowledgements}

This work was supported by grant EP/L016303/1 for Cranfield University, Centre for Doctoral Training in Renewable Energy Marine Structures (REMS) (http://www.remscdt.ac.uk/) from the UK Engineering and Physical Sciences Research Council (EPSRC).

Data underlying this study can be accessed through the Cranfield University repository at https://doi.org/10.17862/cranfield.rd.12129594

\section{References}

[1] Mitsubishi Heavy Industries. First Application of Hybrid Laser-arc Welding to Commercial Ships 2010;47:59-64.

[2] Meyer Werft. Meyer Werft - High-precision laser welding 2020.

[3] Kroos J, Gratzke U, Vicanek M, Simon G. Dynamic Behavior of the Keyhole in Laser welding. J Phy D 1993;26:481-6. https://doi.org/10.1088/0022$3727 / 26 / 3 / 022$.

[4] Courtois M, Carin M, Le Masson P, Gaied S, Balabane M. A complete model of keyhole and melt pool dynamics to analyze instabilities and collapse during laser welding. J Laser Appl 2014;26:042001. https://doi.org/10.2351/1.4886835. 
[5] Kaul R, Ganesh P, Ittop MO, Nath A k., Kumar A, Bhatt RB, et al. Microstructural characterisation of a dissimilar weld of alloy D9 and AISI 316M stainless steel produced using a 2.5 kW CW CO2 laser. Lasers Eng 2002;12:117-33.

[6] Ocelík V, Eekma M, Hemmati I, De Hosson JTM. Elimination of Start/Stop defects in laser cladding. Surf Coatings Technol 2012;206:2403-9.

https://doi.org/10.1016/j.surfcoat.2011.10.040.

[7] Blecher J, Palmer T, DebRoy T. Mitigation of Root Defect in Laser and Hybrid Laser-Arc Welding. Weld J 2015;94:73-82.

[8] Suder W, Ganguly S, Williams S, Yudodibroto B. Root stability in hybrid laser welding. J Laser Appl 2017;29:022410. https://doi.org/10.2351/1.4983161.

[9] Frostevarg J. Factors affecting weld root morphology in laser keyhole welding. Opt Lasers Eng 2018;101:89-98. https://doi.org/10.1016/j.optlaseng.2017.10.005.

[10] Sun $Y$, Cui H, Tang $X$, Lu F. Characterization and formation mechanism of periodic solidification defects in deep-penetration laser welding of NiCrMoV steel with heavy section. Int J Adv Manuf Technol 2019;100:2857-66. https://doi.org/10.1007/s00170-018-2802-3.

[11] Zhang M, Zhang $Y$, Mao C, Hu Y, Chen G, Bi Z. Experiments on formation mechanism of root humping in high-power laser autogenous welding of thick plates with stainless steels. Opt Laser Technol 2019;111:11-9. https://doi.org/10.1016/j.optlastec.2018.09.029.

[12] Gook S, Üstündağ Ö, Gumenyuk A, Rethmeier M. Avoidance of end crater imperfections at high-power laser beam welding of closed circumferential welds. Weld World 2020;64:407-17. https://doi.org/10.1007/s40194-019-00841-x.

[13] Yazdian N, Mohammadpour M, Kong F, Kovacevic R. Hybrid laser/arc girth welding of $304 \mathrm{~L}$ stainless steel tubes, part 1 - Pore mitigation, thermal analysis and mechanical properties. Int J Press Vessel Pip 2018;163:75-93. https://doi.org/10.1016/j.ijpvp.2018.05.003.

[14] Heiple CR, Rope JR, Stagner RT, Aden RJ. Surface Active Element Effects on the Shape of Gta, Laser, and Electron Beam Welds. Weld J (Miami, Fla) 1983;62:72-7.

[15] Wei PS, Chen YH, Ku JS, Ho CY. Active solute effects on surface ripples in electron-beam welding solidification. Metall Mater Trans B Process Metall Mater Process Sci 2003;34:421-32. https://doi.org/10.1007/s11663-003-0068-z.

[16] Ahsan MRU, Cheepu M, Ashiri R, Kim TH, Jeong C, Park Y Do. Mechanisms of weld pool flow and slag formation location in cold metal transfer (CMT) gas metal arc welding (GMAW). Weld World 2017;61:1275-85. https://doi.org/10.1007/s40194-017-0489-y.

[17] Zhao CX, Kwakernaak C, Pan Y, Richardson IM, Saldi Z, Kenjeres S, et al. The effect of oxygen on transitional Marangoni flow in laser spot welding. Acta Mater 2010;58:6345-57. https://doi.org/10.1016/j.actamat.2010.07.056. 
[18] Ribic B, Tsukamoto S, Rai R, DebRoy T. Role of surface-active elements during keyhole-mode laser welding. J Phys D Appl Phys 2011;44.

https://doi.org/10.1088/0022-3727/44/48/485203.

[19] Zhao L, Tsukamoto S, Arakane G, Sugino T, DebRoy T. Influence of oxygen on weld geometry in fibre laser and fibre laser-GMA hybrid welding. Sci Technol Weld Join 2011;16:166-73. https://doi.org/10.1179/1362171810Y.0000000010. 
2020-08-23

Study on effect of laser keyhole weld termination regimes and material composition on weld overlap start-stop defects

\author{
Lai, Wai Jun
}

Elsevier

Lai W-J, Ganguly, Suder W. (2020) Study on effect of laser keyhole weld termination regimes and material composition on weld overlap start-stop defects. Journal of Manufacturing

Processes, Volume 58, October 2020, pp.416-428

https://doi.org/10.1016/j.jmapro.2020.08.012

Downloaded from Cranfield Library Services E-Repository 